\begin{tabular}{|c|c|c|}
\hline & \multicolumn{2}{|c|}{ Journal of Applied Mathematics and Computational Mechanics 2020, 19(3), 71-84 } \\
\hline & $\begin{array}{l}\text { www.amcm.pcz.pl } \\
\text { DOI: } 10.17512 / \text { jamcm.2020.3.06 }\end{array}$ & $\begin{array}{l}\text { p-ISSN 2299-9965 } \\
\text { e-ISSN 2353-0588 }\end{array}$ \\
\hline
\end{tabular}

\title{
HEAT AND MASS TRANSFER FLOW OF NANOFLUIDS IN PRESENCE OF CHEMICAL REACTION WITH PARTIAL SLIP CONDITIONS
}

\author{
G. Narender ${ }^{1}$, K. Govardhan ${ }^{2}$, G. Sreedhar Sarma ${ }^{3}$ \\ ${ }^{1,3}$ Department of Humanities and Sciences (Mathematics), CVR College of Engineering, Hyderabad \\ Telangana State, India \\ ${ }^{2}$ Department of Mathematics, GITAM University, Hyderabad, Telangana State, India \\ gnriimc@gmail.com,govardhan_kmtm@yahoo.co.in,sarma.sreedhar@gmail.com
}

Received: 30 January 2020; Accepted: 6 September 2020

\begin{abstract}
A mathematical model is presented for analyzing the convective fluid over a stretching surface in the presence of nanoparticles. The analysis of heat and mass transfer of converted fluid with slip boundary condition is investigated. To convert the governing Partial Differential Equations (PDEs) into a system of nonlinear Ordinary Differential Equations (ODEs) we use similarity transformations. The shooting method is used to solve the system of ODEs numerically, and obtained numerical results are compared with the published results and found that both are in excellent agreement. The numerical values obtained for the velocity, temperature and concentration profiles are presented through graphs and tables. A discussion on the effects of various physical parameters and heat transfer characteristics is also included.
\end{abstract}

MSC 2010: 76D05, 76D10

Keywords: Brownian motion, stretching sheet, thermophoresis, similarity solution, partial slips, chemical reaction

\section{Introduction}

The transfer of heat by the movement of fluids from one place to another is called convective heat transfer. Convective heat transfer is a combination of heat diffusion and bulk fluid flow that are called conduction and advection simultaneously. In engineering problems convective heat transfer has wide applications. A large number of investigations on nanofluids (i.e. mixture of fluid and nanoparticles) shows that it can improve thermal conductivity in fluids. Nanofluid is a fluid containing nanometer-sized particles called nanoparticles. These nanoparticles are made of metals, oxides, carbides etc. Nanofluids have properties that make them potentially useful in many heat transfer applications. They exhibit enhanced 
thermal conductivity and a convective heat transfer coefficient. Choi [1] studied the enhancing thermal conductivity of fluid with nanoparticles. Eastman et al. [2] have reviewed the detailed work done on convective transport in nanofluid. The different theories of heat transfer in nanofluids are discussed by Boungiorno [3]. Kuznetsov and Nield [4], who studied the convective nanofluid in a vertical plate. Later they extended their work for porous medium as well [5].

In [6], Ramesh and Gireesha considered the heat source/sink of Maxwell fluid over a stretching sheet with a convective boundary condition in boundary layer flow in the presence of nanoparticles. In recent years, MHD flows of viscoelastic fluids with or without heat transfer over a stretching sheet have also been addressed by some researchers [7-11]. Bhattacharyya et al. [12] analyzed the convection flow of boundary layer force and heat transfer past a porous plate with velocity and temperature slip effect. Das [13] observed the impact of partial slip, thermal radiation, chemical reaction, and temperature dependent fluid properties with constant heat flux over a premeable plate and nonuniform heat source/sink. Zheng et al. [14] analyzed the effect of velocity slip on MHD flow and heat transfer over a porous sheet. Recently, the influence of partial slip flow and heat transfer over a stretching sheet in a nanofluid are examined by Sharma et al. [15]. The impact of nanofluids on the performance enhancement of a photovoltaic thermal system was analyzed by Naseem Abbas et al. [16]. Samina Javed et al. [17] discussed the issue of convection heat transfer of nanofluids in different flow regimes for different heat transfer devices. In addition, many significant features of the MHD flow past a stretching sheet were presented and elaborated in the literature [18-23].

In this article, we present a review study of Aminrezan Noghrehabadi et al. [24] and then extend the flow analysis with variable thermophysical properties. Also, a comparison of the obtained numerical results with the published results of [24] has been made and found that both are in excellent agreement.

\section{Mathematical modelling}

A two-dimensional boundary layer flow of a study, viscous and incompressible nanofluid flow through a plate in a porous medium has been considered with focus on the heat and mass transfer. The geometry of the flow model is shown in Figure 1. From the slot at the origin thin solid surface is extruded which is being stretched in $x$-direction. The stretching velocity $u_{w}(x)=c x$ is assumed to vary linearly from the origin, here $c$ is a positive constant $(c>0)$. It is also assumed that the temperature and nanofluid volume fraction at the surface of the sheet are respectively $T_{w}$ and $C_{w}$ while the uniform temperature and the nanofluid volume fraction far from the surface of the sheet are $T_{\infty}$ and $C_{\infty}$, respectively as $y$ tends to $\infty$. The flow is described by the equation of continuity, equation of momentum and energy equation as: 


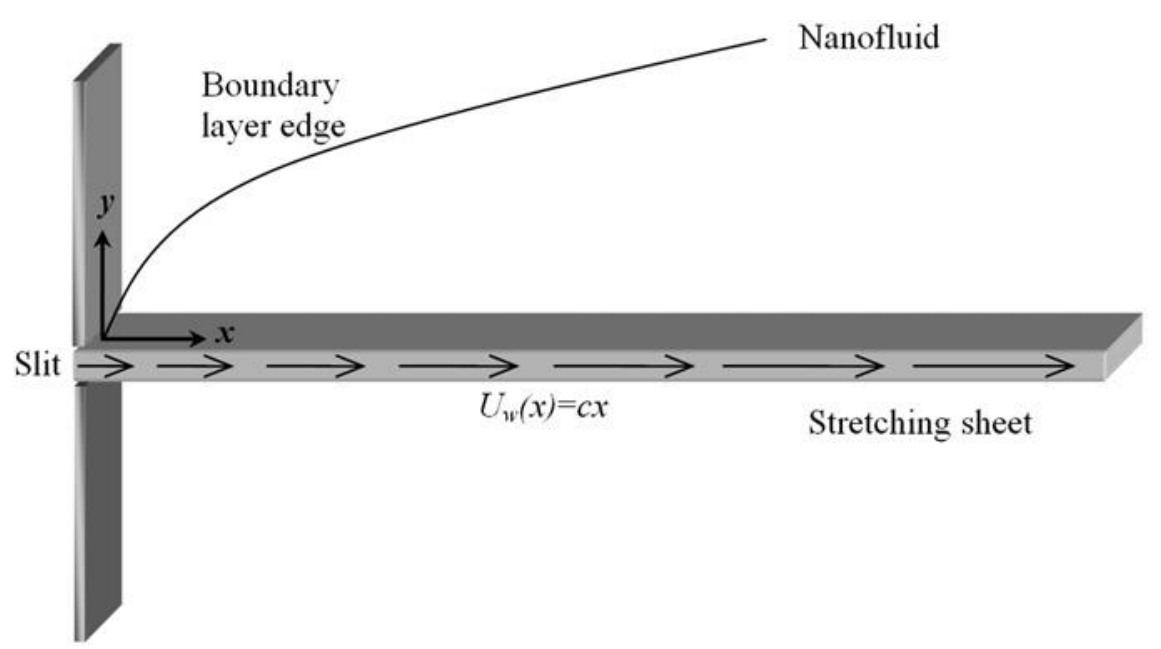

Fig. 1. Physical model and coordinate system

\section{Continuity equation}

Physical principal: Mass is conserved

$$
\frac{\partial u}{\partial x}+\frac{\partial v}{\partial y}=0
$$

\section{Momentum equation}

Physical principle: $\mathrm{F}=$ ma

$$
\frac{\partial u}{\partial x} u+\frac{\partial u}{\partial y} v=-\frac{1}{\rho_{f}} \frac{\partial p}{\partial x}+v\left(\frac{\partial^{2} u}{\partial x^{2}}+\frac{\partial^{2} u}{\partial y^{2}}\right)
$$

In equation (2) $u$ and $v$ are the components of velocity respectively in the $x$ and $y$ directions, $p$ is the fluid pressure, $\rho_{f}$ is the density of base fluid, $\rho_{p}$ is the density of the particles, $v$ is the kinematic viscosity of the base fluid.

\section{Energy equation}

Physical principle: Energy is conserved

By using the boundary layer approximations, the boundary layer equation of energy for fluid temperature $T$ is

$$
\begin{aligned}
\frac{\partial T}{\partial x} u+\frac{\partial T}{\partial y} v & =\tau\left\{D_{B}\left(\frac{\partial C}{\partial x} \frac{\partial T}{\partial y}+\frac{\partial C}{\partial x} \frac{\partial T}{\partial y}\right)+\frac{D_{T}}{T_{\infty}}\left\{\left(\frac{\partial T}{\partial x}\right)^{2}+\left(\frac{\partial T}{\partial y}\right)^{2}\right\}\right\} \\
& +\alpha\left(\frac{\partial^{2} T}{\partial x^{2}}+\frac{\partial^{2} T}{\partial y^{2}}\right)
\end{aligned}
$$




\section{Mass transfer equation}

$$
\frac{\partial C}{\partial x} u+\frac{\partial C}{\partial y} v=D_{B}\left(\frac{\partial^{2} C}{\partial x^{2}}+\frac{\partial^{2} C}{\partial y^{2}}\right)-\frac{D_{T}}{T_{\infty}}\left(\frac{\partial^{2} T}{\partial x^{2}}+\frac{\partial^{2} T}{\partial y^{2}}\right)-K_{0}\left(C-C_{\infty}\right) .
$$

In equations (3) and (4) $\alpha$ is the thermal diffusivity of the base fluid, $\tau=\frac{(\rho c)_{p}}{(\rho c)_{f}}$ is the ratio of nanoparticle heat capacity and the base fluid heat capacity, $D_{B}$ is the Brownian diffusion coefficient, $D_{T}$ is the thermophoresis diffusion coefficient, $C$ is rescaled nanoparticle volume fraction and $T$ is the local temperature. The associated boundary conditions for the above system of equations are:

$$
\left.\begin{array}{l}
u=U_{w}(x)-U_{s}, v=0, T=T_{w} C=C_{w} \text { at } y=0 \\
u=v=0, T=T_{\infty}, C=C_{\infty} \text { as } y \rightarrow \infty
\end{array}\right\}
$$

\section{Similarity transformation}

In this section, we convert the system of Eqs. (1)-(4) along with the boundary conditions (5) into a dimensionless form. To find out the solution of our model, we use the following similarity transformation:

$$
\eta=y \sqrt{\frac{c}{v}}, \psi=\sqrt{c v x} f(\eta), \theta(\eta)=\frac{T-T_{\infty}}{T_{f}-T_{\infty}}, \beta(\eta)=\frac{C-C_{\infty}}{C_{w}-C_{\infty}} .
$$

As above, $\psi(x, y)$ denotes stream function obeying

$$
u=\frac{\partial \psi}{\partial y}, v=-\frac{\partial \psi}{\partial x}
$$

The equation of continuity (1) is satisfied identically. By applying the similarity transformations on the remaining three equations i.e. the momentum Eq. (2), the temperature Eq. (3) and concentration Eq. (4), the similarity equations are otained as follows:

$$
\begin{gathered}
f^{\prime \prime \prime}+f f^{\prime \prime}-\left(f^{\prime}\right)^{2}=0, \\
\theta^{\prime \prime}+\operatorname{Pr}\left(f \theta^{\prime}+N b \beta^{\prime} \theta^{\prime}+N t\left(\theta^{1}\right)^{2}\right)=0, \\
\beta^{\prime \prime}+\operatorname{Le}\left(f \beta^{\prime}-f^{\prime} \beta\right)+\frac{N t}{N b} \theta^{\prime \prime}-K_{c} L e \beta=0 .
\end{gathered}
$$


The transformed boundary conditions are:

$$
\left.\begin{array}{l}
f(0)=0, f^{\prime}(0)=1+\lambda f^{\prime \prime}(0), \theta(0)=1, \beta(0)=1 \text { at } y=0 \\
f^{\prime}(\infty) \rightarrow \in, \theta(\infty) \rightarrow 0, \beta(\infty) \rightarrow 0 \text { as } \eta \rightarrow \infty
\end{array}\right\}
$$

In Eqs. (8)-(9), the governing parameters are defined as: $\operatorname{Pr}=\frac{v_{f}}{\alpha}$ is Prandtl number, $L e=\frac{\alpha}{D_{B}}$ is Lewis number, $N b=\frac{\tau D_{B}\left(C_{f}-C_{\infty}\right)}{v_{f}}$ is Brownian motion parameter, $N t=\frac{\tau D_{T}\left(T_{f}-T_{\infty}\right)}{v_{f} T_{\infty}}$ is thermophoresis parameter and $K_{c}=\frac{k_{0}}{a}$ is the chemical reaction parameter, $\lambda=N \rho(c v)^{\frac{1}{2}}$ is the dimensionless slip factor.

In this problem, the desired physical quantities are the local Nusselt number $N u_{x}$, reduced Sherwood number $S h_{x}$ and the skin-friction coefficient $C_{f}$. These quantities are defined as

$$
C_{f}=\frac{\tau_{w}}{\rho U_{w}^{2}}, N u_{x}=\frac{x q_{w}}{k_{f}\left(T_{w}-T_{\infty}\right)}, S h=\frac{x h_{m}}{D_{B}\left(\phi_{w}-\phi_{\infty}\right)}
$$

Here, $\tau_{w}$ is the shear stress along the stretching surface, $q_{w}$ is the heat flux from the stretching surface and $h_{m}$ is the wall mass flux, and are given as

$$
\tau_{w}=\mu\left(\frac{\partial u}{\partial y}\right)_{y=0}, q_{w}=-k\left(\frac{\partial T}{\partial y}\right)_{y=0}, h_{m}=-D_{B}\left(\frac{\partial C}{\partial z}\right)_{y=0}
$$

With the help of above equations, we get

$$
C_{f} \sqrt{\operatorname{Re}_{x}}=-f^{\prime \prime}(0), \frac{N u_{x}}{\sqrt{\operatorname{Re}_{x}}}=-\theta^{\prime}(0), \frac{S h_{x}}{\sqrt{\mathrm{Re}_{x}}}=-\beta^{\prime}(0)
$$

where $\operatorname{Re}_{x}=\frac{x U_{w}}{v}$ is the local Reynolds number.

\section{Solution methodology}

The analytical solution of the system of Eqs. (8)-(10) together with boundary conditions (11) cannot be found because they are coupled and nonlinear in nature. These nonlinear coupled ODEs are solved numerically by the shooting technique. 
To apply this technique, we first convert the system of ODEs of higher order into the system of ODEs of first order.

By using the following notations,

$$
f=y_{1}, f^{\prime}=y_{2}, f^{\prime \prime}=y_{3}, \theta=y_{4}, \theta^{\prime}=y_{5}, \beta=y_{6}, \beta^{\prime}=y_{7}
$$

the system of first order ODEs are:

$$
\begin{array}{ll}
y_{1}^{\prime}=y_{2}, & y_{1}(0)=0 \\
y_{2}^{\prime}=y_{3}, & y_{2}(0)=1+\lambda y_{3}(0) \\
y_{3}^{\prime}=y_{2}^{2}-y_{1} y_{3}, & y_{3}(0)=Y_{3}(0) \\
y_{4}^{\prime}=y_{5}, & y_{4}(0)=1 \\
y_{5}^{\prime}=\operatorname{Pr}\left(y_{1} y_{5}+N b y_{7} y_{5}+N t y_{5}^{2}\right) y_{3}, & y_{5}(0)=Y_{5}(0) \\
y_{6}^{\prime}=y_{7}, & y_{6}(0)=1 \\
y_{7}^{\prime}=- \text { Ley }_{1} y_{7}-\frac{N t}{N b} y_{5}^{\prime}+\operatorname{LeK}_{c} y_{6}, & y_{7}(0)=Y_{7}(0)
\end{array}
$$

To solve the above system of equations, the unbounded domain $\left[0, \eta_{\infty}\right]$ is restricted to a bounded domain $\left[0, \eta_{e}\right]$, where $\eta_{e}=8$. This is due to the fact that increasing the value of $\eta_{e}$ beyond 8 gives negligible variation in the numerical results. In the modeled problem, $Y_{3}(0), Y_{5}(0)$ and $Y_{7}(0)$ are initial guesses which are required to solve the above first order system of ordinary differential equations with fourth order Adams-Moultan method. The Newton iterative scheme is used to refine those initial guesses. The iterative process is repeated until the following criteria is met.

$\max \left\{\left|y_{2}\left(\eta_{\infty}\right)\right|,\left|y_{4}\left(\eta_{\infty}\right)\right|,\left|y_{6}\left(\eta_{\infty}\right)\right|\right\}<\varepsilon$, where $\varepsilon>0$ is the tolerance.

For all computation in this paper, we have fixed $\varepsilon=10^{-5}$. The step sizes of $\Delta \eta=0.01$ and $\eta_{\max }=8$ were found to be satisfactory in obtaining sufficient accuracy.

\section{Code validation}

The comparison of present results with those obtained by Gorla and Sidawi [9], Khan and Pop [10] corresponding to $-\theta^{\prime}(0)$ and $-\beta^{\prime}(0)$ when $\operatorname{Pr}=10, L e=10$, 
$K_{c}=0, \lambda=0$ is presented in Table 1. Excellent agreement of current results with those previously published results encourage us to use the present code.

Furthermore, in Table 2, we reproduce the results of Aminreza Noghrehabadi [24] for the shear stress at surface $f^{\prime \prime}(0)$ and $f(\infty)$. Both the physical parameters $C_{f}$, Nur and Shr are of great interest to engineers. $C_{f}$ is the one which examines the viscus stress acting on the surface of the plate.

In Table 3, we discussed the effects of the slip parameter and reaction rate parameter on Nusselt number Nur, Sherwood number Shr, skin-friction coefficient $C_{f}$. It is observed in the table that increasing the values of $\lambda$ and $K_{c}$, Nusselt number, Sherwood number and skin-friction decreases.

Table 1. Comparison of results for the Nusselt number $-\theta^{\prime}(0)$ and Sherwood number $-\beta^{\prime}(0)$ when $\operatorname{Pr}=10, L e=10, K_{c}=0$

\begin{tabular}{|c|c|c|c|c|c|c|c|}
\hline \multirow{2}{*}{$N t$} & \multirow{2}{*}{$N b$} & \multicolumn{3}{|c|}{ Nur } & \multicolumn{3}{c|}{ Shr } \\
\cline { 3 - 8 } & & {$[8]$} & {$[9]$} & $\begin{array}{c}\text { Present } \\
\text { results }\end{array}$ & {$[8]$} & {$[9]$} & $\begin{array}{c}\text { Present } \\
\text { results }\end{array}$ \\
\hline 0.1 & 0.1 & 0.9524 & 0.95243 & 0.9523807 & 2.1294 & 2.12936 & 2.129389 \\
\hline 0.2 & 0.1 & 0.6932 & 0.69331 & 0.6931774 & 2.2740 & 2.27404 & 2.274013 \\
\hline 0.3 & 0.1 & 0.5201 & 0.52010 & 0.5200807 & 2.5286 & 2.52862 & 2.528628 \\
\hline 0.4 & 0.1 & 0.4026 & 0.40264 & 0.4025821 & 2.7952 & 2.79511 & 2.795159 \\
\hline 0.5 & 0.1 & 0.3211 & 0.32116 & 0.3210552 & 3.0351 & 3.03519 & 3.035133 \\
\hline 0.1 & 0.2 & 0.5056 & 0.50565 & 0.5055822 & 2.3819 & 2.38182 & 2.381871 \\
\hline 0.1 & 0.3 & 0.2522 & 0.25228 & 0.2521539 & 2.4100 & 2.40995 & 2.410021 \\
\hline 0.1 & 0.4 & 0.1194 & 0.11948 & 0.1194019 & 2.3997 & 2.39960 & 2.399653 \\
\hline 0.1 & 0.5 & 0.0543 & 0.05429 & 0.0542493 & 2.3836 & 2.38353 & 2.383574 \\
\hline
\end{tabular}

Table 2. Comparison of results for the shear stress at surface $-f^{\prime \prime}(0)$ and $f(\infty)$ with the slip factor $\lambda$

\begin{tabular}{|c|c|c|c|c|c|c|c|}
\hline \multirow{2}{*}{$\lambda$} & \multicolumn{3}{|c|}{$-f^{\prime \prime}(0)$} & \multicolumn{4}{c|}{$f(\infty)$} \\
\cline { 2 - 8 } & $\begin{array}{c}\text { Shoo and } \\
\text { Do [7] }\end{array}$ & {$[24]$} & $\begin{array}{c}\text { Current } \\
\text { results }\end{array}$ & $\begin{array}{c}\text { Shoo and } \\
\text { Do [7] }\end{array}$ & $\begin{array}{c}\text { Wang } \\
{[11]}\end{array}$ & {$[24]$} & $\begin{array}{c}\text { Current } \\
\text { results }\end{array}$ \\
\hline 0.0 & 1.001154 & 1.0 & 1.0 & 1.001483 & 1.0 & 1.0 & 1.0 \\
\hline 1.0 & 0.428450 & 0.430160 & 0.4302 & 0.752226 & 0.7549 & 0.754866 & 0.7548 \\
\hline 3.0 & 0.213314 & 0.214055 & 0.2141 & 0.590892 & 0.5982 & 0.598077 & 0.5976 \\
\hline 10 & 0.081091 & 0.081243 & 0.08125 & 0.413655 & 0.4331 & 0.431976 & 0.4297 \\
\hline
\end{tabular}


Table 3. Numerical results of the Nusselt number, Sherwood number, skin-friction coefficient with $K_{c}$ and slip parameter $\lambda$ for $N t=N b=0.1$ and $\operatorname{Pr}=10$

\begin{tabular}{|c|c|c|c|c|c|c|c|c|}
\hline$K_{c}$ & \multicolumn{2}{|c|}{-0.1} & \multicolumn{2}{c|}{0} & \multicolumn{2}{c|}{0.1} & \multicolumn{2}{c|}{0.3} \\
\hline$\lambda$ & Nur & Shr & Nur & Shr & Nur & Shr & Nur & Shr \\
\hline 0 & 0.98059 & 1.8237 & 0.9523 & 2.12939 & 0.9285 & 2.4048 & 0.89 & 2.8864 \\
\hline 1 & 0.7590 & 1.1838 & 0.7189 & 1.6074 & 0.6889 & 1.9598 & 0.648 & 2.5293 \\
\hline 3 & 0.6261 & 0.7010 & 0.5697 & 1.2738 & 0.5345 & 1.6991 & 0.4921 & 2.3294 \\
\hline 10 & 0.5207 & 0.0575 & 0.4124 & 0.9221 & 0.3707 & 1.4566 & 0.3332 & 2.1409 \\
\hline
\end{tabular}

\section{Graphical results}

Figure 2 shows the variations in the velocity profile $f^{\prime}(\eta)$ and shear stress at surface $f^{\prime \prime}(\eta)$ for different estimations of slip parameter $\lambda$. It is analyzed that velocity profile $f^{\prime}(\eta)$ decreases when we increase slip parameter $\lambda$, however on the opposite side shear stress at surface $f^{\prime \prime}(\eta)$ increases.

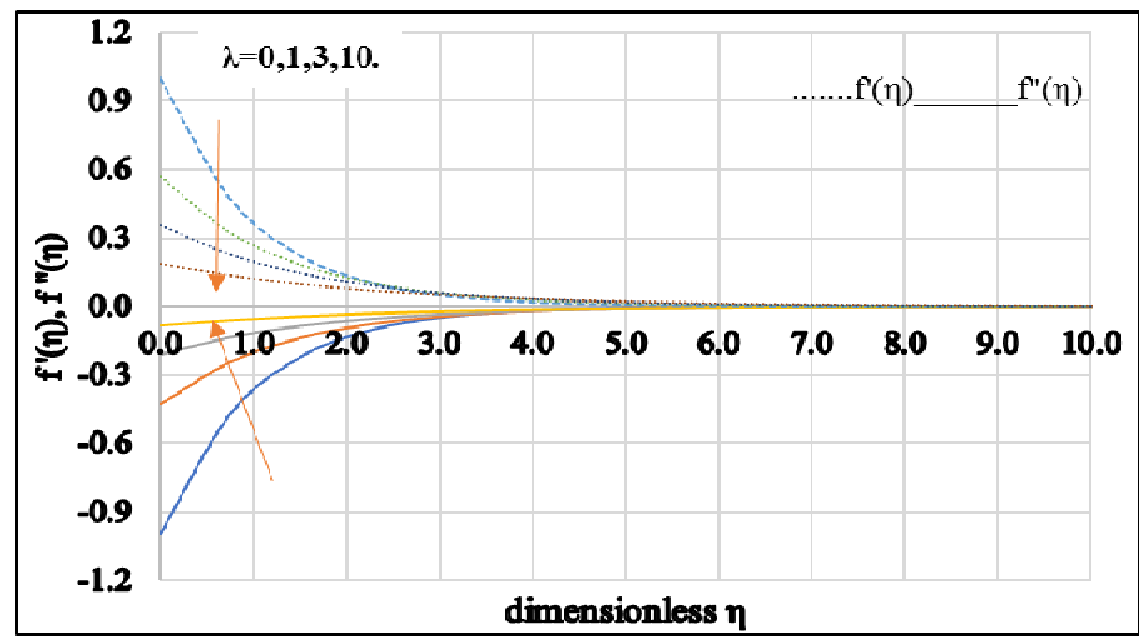

Fig. 2. Plots of dimensionless similarity functions $f^{\prime}(\eta), f^{\prime \prime}(\eta)$ for various values of $\lambda$

From Figures 3 and 4, it was observed that the chemical reaction parameter reduces the temperature profiles. This is true because as a chemical reaction takes place, the number of nanoparticles within the fluid is becomes smaller and smaller. 


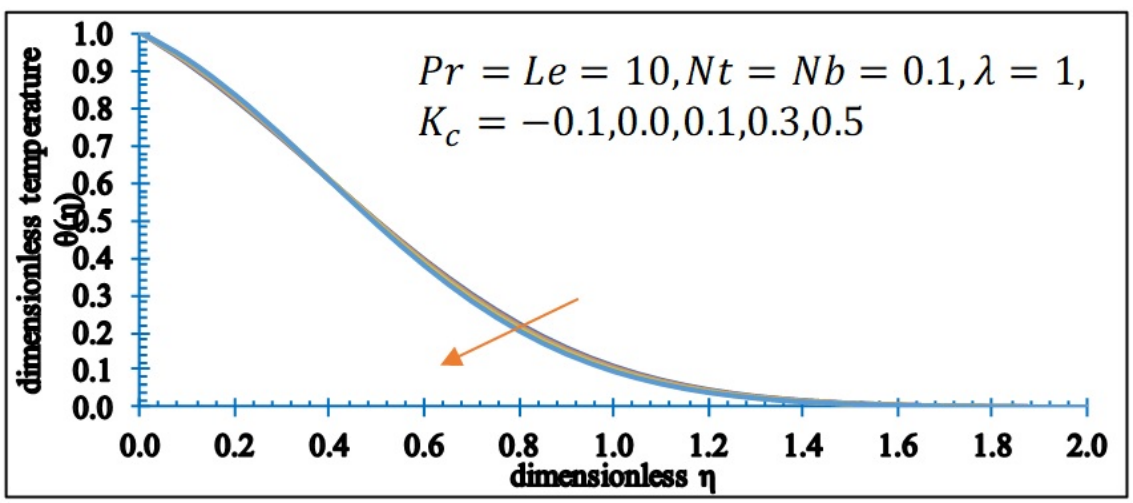

Fig. 3. Impact of $K_{c}$ on $\theta$

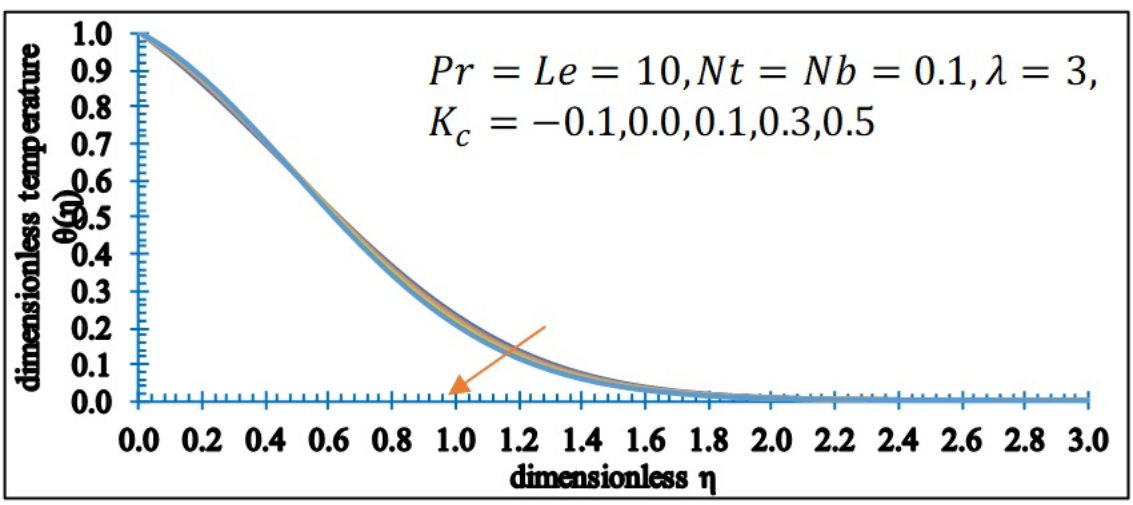

Fig. 4. Impact of $K_{c}$ on $\theta$

Figures 5 and 6 show the impact of the chemical reaction together with $\lambda$ on the dimensionless concentration. In these figures, it also observed that when the chemical reaction increases, the concentration profiles decrease, and the increasing values of the slip factor have a minor impact on the dimensionless concentration.

Figures 7-9 illustrate the combined effect of slip parameter $\lambda$ and chemical reaction parameter $K_{c}$ on the Nusselt number $-\theta^{\prime}(0)$. It is observed that the Nusselt number is a decreasing function of $\lambda$ and $K_{c}$. Hence, to achieve a high rate of heat transfer, less slip on the fluid-solid interface is desired.

Figures 10-12 show the dimensionless mass transfer rate $-\beta^{\prime}(0)$ plotted against Thermophoresis parameter $N t$ for the different values of chemical reaction parameter $K_{c}$ and slip parameter $\lambda$. It is verified that there is a increase in the mass transfer rate as chemical reaction parameter $K_{c}$ increases. 


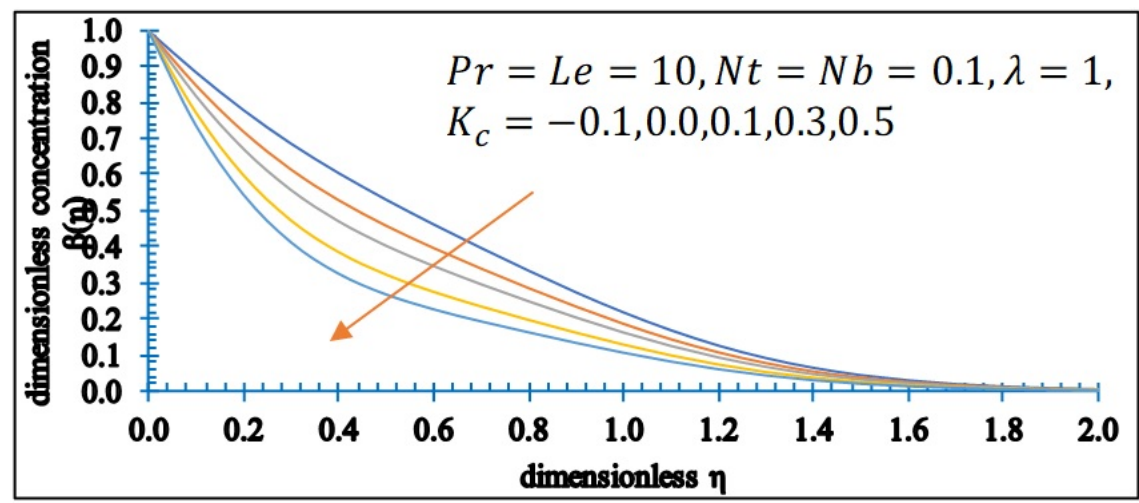

Fig. 5. Impact of $K_{c}$ on $\beta$

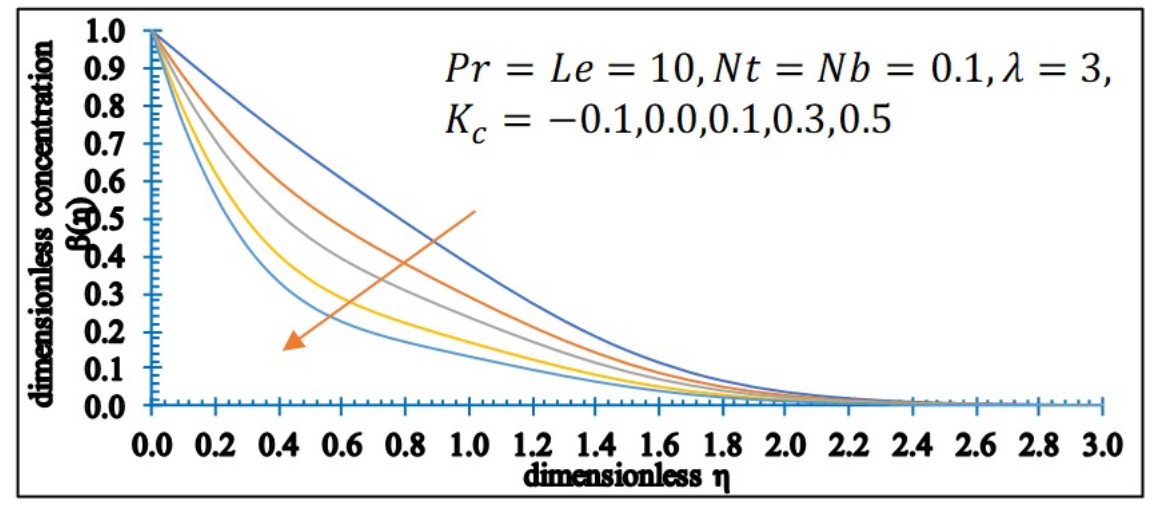

Fig. 6. Impact of $K_{c}$ on $\beta$

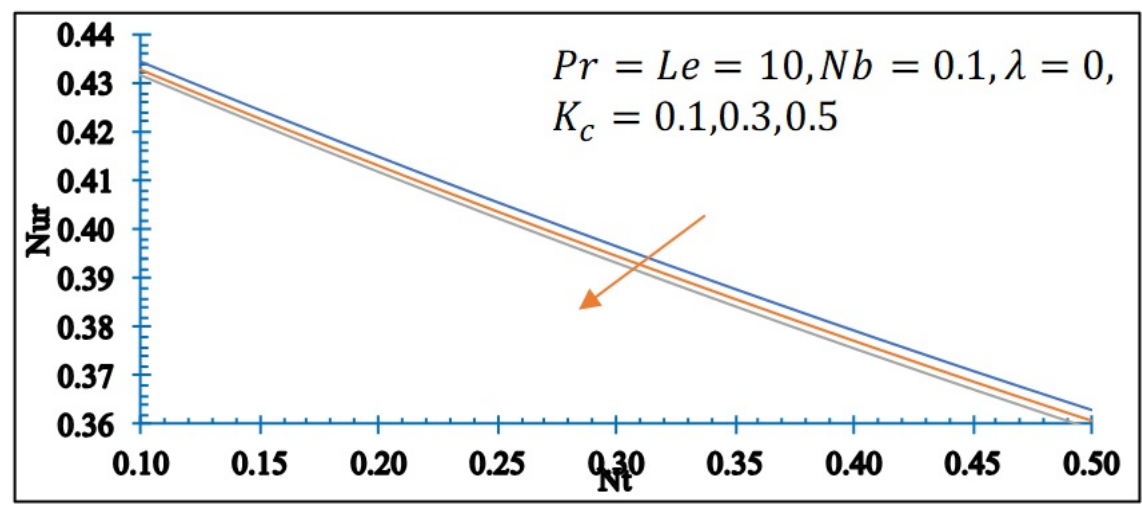

Fig. 7. Heat transfer rate $v s N t$ for several values of $K_{c}$ 


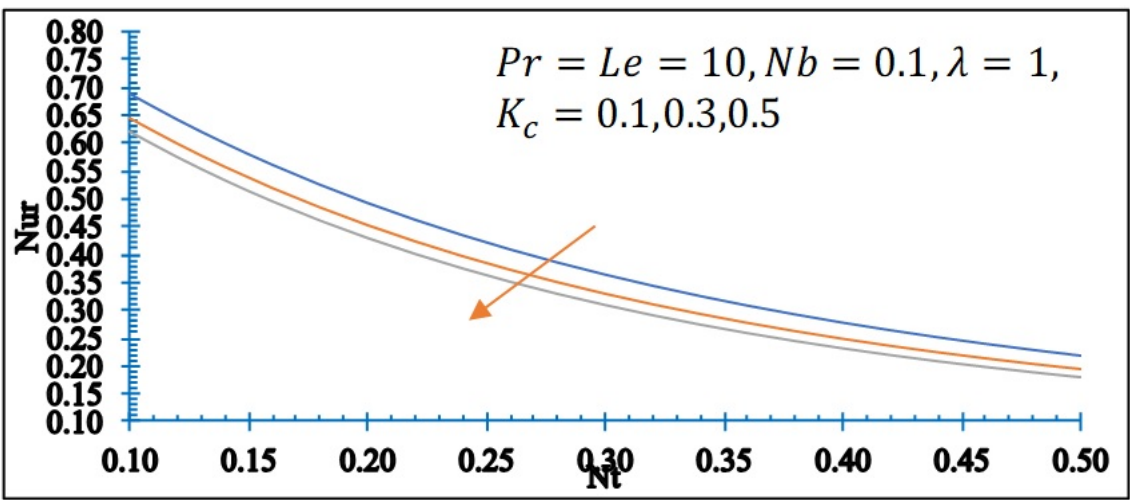

Fig. 8. Heat transfer rate $v s N t$ for several values of $K_{c}$

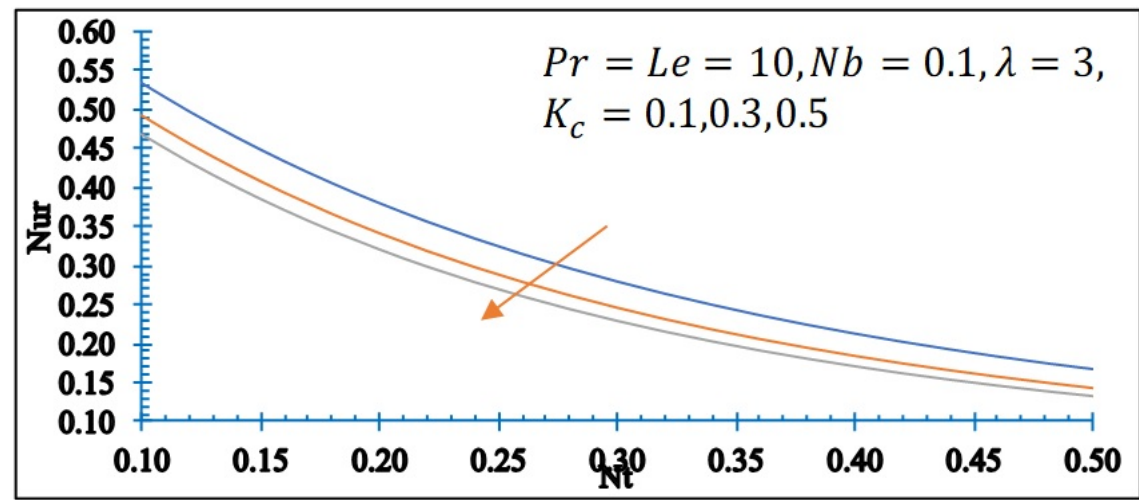

Fig. 9. Heat transfer rate $v s N t$ for several values of $K_{c}$

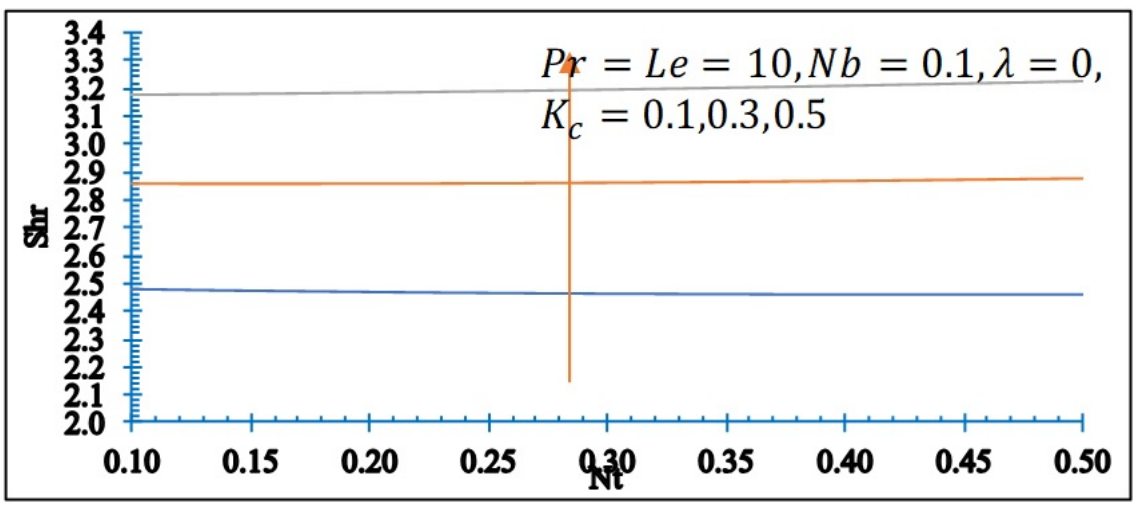

Fig. 10. Mass transfer rate $v s N t$ for several values of $K_{c}$ 


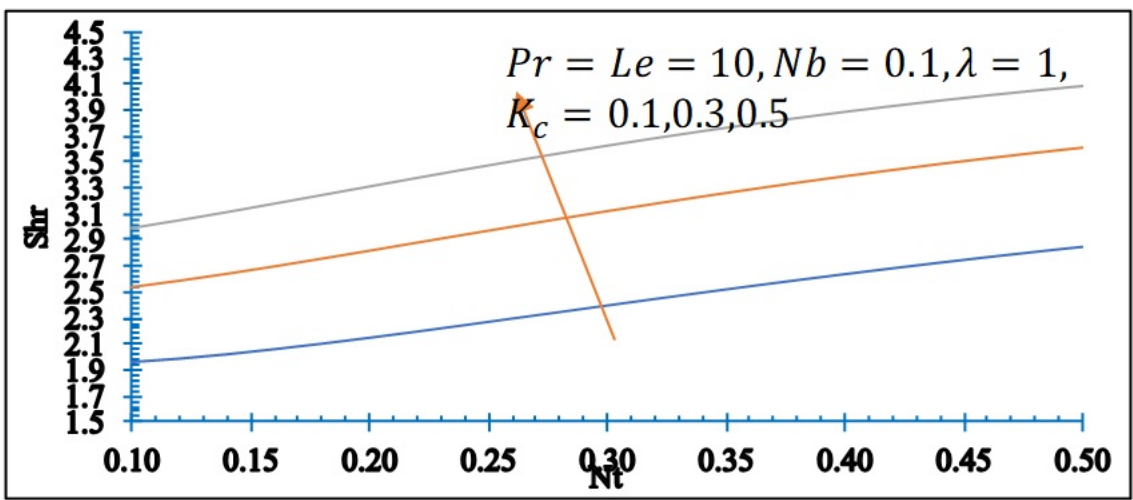

Fig. 11. Heat transfer rate $v s N t$ for several values of $K_{c}$

\section{Conclusion}

After a thorough investigation, we have reached the following concluding observation. It is observed that the increase in slip parameter the momentum boundary layer thickness increases, whereas velocity profile decreases. It also observed that the chemical reaction parameter increases with a decrease in the concentration profile. The heat transfer rate at the plate surface decreases with increasing $\lambda$ and $K_{c}$. The mass transfer rate increases with an increase in the chemical reaction parameter.

\section{Acknowledgement}

Help by Prof. S.R. Koneru, Retd. Professor, Department of Mathematics, IIT Mumbai in the preparation of this paper is gratefully acknowledged. The authors also wish to express their thanks to the very competent Reviewers for their very good comments and suggestions.

\section{Nomenclature}

a - constant

$c_{f} \quad$ - heat capacity of the fluid

$c_{p} \quad$ effective heat capacity $\left[\mathrm{J} \cdot \mathrm{kg}^{-1} \cdot \mathrm{K}^{-1}\right]$

$D_{B}$ - Brownian diffusion coefficient

$D_{T}-$ thermophoretic diffusion coefficient

$k_{0} \quad$ - chemical reaction coefficient $\left[\mathrm{s}^{-1}\right]$

Le - Lewis number

$M$ - magnetic parameter

$\mathrm{Nb}$ - Brownian motion parameter

$\mathrm{Nr}$ - radiation parameter 
$N t$ - thermophoresis parameter

$\mathrm{Nu}$ - Nusselt number

Nur - reduced Nusselt number

Pr - Prandtl number

$p \quad$ - pressure

$q_{m} \quad$ wall mass flux

$q_{w} \quad-$ wall heat flux

$R e_{x}$ - local Reynolds number

Shr - reduced Sherwood number

$S h_{x}$ - local Sherwood number

$T$ - fluid temperature

$T_{w}$ - temperature at the stretching sheet

$T_{\infty}$ - ambient temperature

$u, v$ - velocity components along the $x$ and $y$ axis

$u_{w}$ - velocity of the stretching surface

$x, y$ - Cartesian coordinates ( $x$ axis is aligned along the stretching surface and $y$ axis is perpendicular to it)

$\alpha \quad-$ thermal diffusivity

$\beta$ - dimensionless nanoparticle volume fraction

$\eta \quad$ - similarity variable

$\theta-$ dimensionless temperature

$\xi \quad-$ thermal conductivity $\left[\mathrm{W} \cdot \mathrm{m}^{-1} \cdot \mathrm{K}^{-1}\right]$

$\rho_{f} \quad-$ density of fluid

$\rho_{p} \quad-$ mass density

$\sigma \quad$ - fluid electrical conductivity

$\tau \quad$ - parameter defined by the ratio between the effective heat capacity of the nanoparticle material and heat capacity of the fluid; $\tau=(\rho c)_{p} /(\rho c)_{f}$

$K_{c}-$ chemical reaction parameter

\section{References}

[1] Choi, S.U.S. (1995). Enhancing thermal conductivity of fluids with nanoparticles. ASMEPublications-Fed, 231, 99-106.

[2] Eastman, J.A., Phillpot, S.R., Choi, S.U.S., \& Keblinski, P. (2004). Thermal transport in nanofluids. Annual Review of Materials Research, 34, 219-246.

[3] Buongiorno, J. (2006). Convective transport in nanofluids. Journal of Heat Transfer, 128(3), 240-250.

[4] Kuznetsov, A.V., \& Nield, D.A. (2010). Natural convective boundary-layer flow of a nanofluid past a vertical plate. International Journal of Thermal Sciences, 49(2), 243-247.

[5] Kuznetsov, A.V., \& Nield, D.A. (2014). Natural convective boundary-layer flow of a nanofluid past a vertical plate: A revised model. International Journal of Thermal Sciences, 77, 126-129. 
[6] Ramesh, G.K., \& Gireesha, B.J. (2014). Influence of heat source/sink on a Maxwell fluid over a stretching surface with convective boundary condition in the presence of nanoparticles. Ain Shams Engineering Journal, 5(3), 991-998.

[7] Sahoo, B., \& Do, Y. (2010). Effects of slip on sheet-driven flow and heat transfer of a thirdgrade fluid past a stretching sheet. International Communications in Heat and Mass Transfer, 37, 1064-1071.

[8] Mania Goyal \& Rama Bhar gava (2013). Numerical Solution of MHD Viscoelastic Nanofluid Flow over a Stretching Sheet with Partial Slip and Heat Source/Sink. Hindawi Publishing Corporation, ISRN Nanotechnology, 2013, Article ID 931021, 11 pages.

[9] Reddy Gorla, R.S., \& Sidawi, I. (1994). Free convection on a vertical stretching surface with suction and blowing. Applied Scientific Research, 52(3), 247-257.

[10] Khan, W.A., \& Pop, I. (2010). Boundary-layer flow of a nanofluid past a stretching sheet. International Journal of Heat and Mass Transfer, 53, 2477-2483.

[11] Wang, C.Y. (2009). Analysis of viscous flow due to a stretching sheet with surface slip and suction. Nonlinear Analysis: Real World Applications, 10(1), 375-380.

[12] Bhattacharyya, K., Mukhopadhyay, S., \& Layek, G.C. (2011). Steady boundary layer slip flow and heat transfer over a flat porous plate embedded in a porous media. Journal of Petroleum Science and Engineering, 78(2), 304-309.

[13] Das, K. (2012). Slip effects on heat and mass transfer in MHD micropolar fluid flow over an inclined plate with thermal radiation and chemical reaction. International Journal for Numerical Methods in Fluids, 70(1), 96-113.

[14] Zheng, L., Niu, J, Zhang, X., \& Gao, Y. (2012). MHD flow and heat transfer over a porous shrinking surface with velocity slip and temperature jump. Mathematical and Computer Modelling, 56(5), 133-144.

[15] Sharma, R., Ishak, A., \& Pop, I. (2013). Partial slip flow and heat transfer over a stretching sheet in a nanofluid. Mathematical Problems in Engineering, 2013.

[16] Abbas, N., Awan, M.B., Amer, M., Ammar, S.M., Sajjad, U., Ali, H.M., Zahra, N., Hussain, M., Badshah, M.A., \& Jafry, A.T. (2019). Applications of nanofluids in photovoltaic thermal systems: A review of recent advances. Physica A: Statistical Mechanics and its Applications, 536, 122513.

[17] Javed, S., Ali, H.M., Babar, H., Khan, M.S., Janjua, M.M., \& Bashir, M.A. (2020). Internal convective heat transfer of nanofluids in different flow regimes: A comprehensive review. Physica A: Statistical Mechanics and its Applications, 538, 122783.

[18] Ahmadlouydarab, M., Ebadolahzadeh, M., \& Ali, H.M. (2020). Effects of utilizing nanofluid as working fluid in a lab-scale designed FPSC to improve thermal absorption and efficiency. Physica A: Statistical Mechanics and its Applications, 540, 123109.

[19] Babar, H., \& Ali, H.M. (2019). Airfoil shaped pin-fin heat sink: Potential evaluation of ferric oxide and titania nanofluids. Energy Conversion and Management, 202, 112194.

[20] Kilica, M., \& Ali, H.M. (2019). Numerical investigation of combined effect of nanofluids and multiple impinging jets on heat transfer. Thermal Science, 23(5), 3165-3173.

[21] Khan, A., \& Ali, H.M. (2019). A comprehensive review - pool boiling using nanofluids. Thermal Science, 23(5), 3209-3237.

[22] Riedler, J., \& Schneider, W. (1983). Viscous flow in corner regions with a moving wall and leakage of fluid. Acta Mechanica, 48, 95-102.

[23] Romano, F., \& Kuhlmann, H.C. (2017). Particle-boundary interaction in a shear-driven cavity flow. Theoretical and Computational Fluid Dynamics, 31, 427-445.

[24] Aminreza, N., Pourrajab, R., \& Ghalambaz, M. (2012). Effect of partial slip boundary condition on the flow and heat transfer of nanofluids past stretching sheet prescribed constant wall temperature. International Journal of Thermal Sciences, 54, 253-261. 